\title{
A Case of Hydatid Cyst Mimicking Kidney Tumor
}

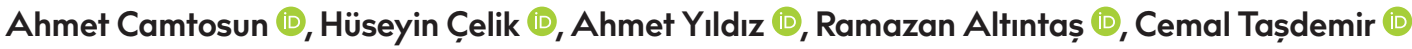 \\ Department of Urology, İnönü University School of Medicine, Malatya, Turkey
}

ORCID IDs of the authors: A.C. 0000-0002-5390-9088; H.C̣. 0000-0002-7180-4845; A.Y. 0000-0003-2968-6758; R.A. 0000-0003-3I453005; C.T. 0000-000I-57I0-689I.

\begin{abstract}
Cite this article as: Camtosun A, Çelik H, Yıldız A, Altıntaș A, Tașdemir C. A Case of Hydatid Cyst Mimicking Kidney Tumor. Cyprus J Med Sci 2019; 4(1): 70-2.

A 45-year-old male patient presented with left flank pain that started a month ago. There was no history of fever or pyuria. Vital signs were normal. The rest of the systemic examination was unremarkable. There were no pathological findings on urinalysis or urine cytology Ultrasonography revealed an $8 \times 6.2 \times 6 \mathrm{~cm}$ heterogeneous exophytic trending lesion at the lower pole of the left kidney. The lesion's walls were seen to be calcified in places, and the margin between the kidney and lesion was indistinct. It could not be differentiated by ultrasonography if the lesion is a complicated cyst or a mass. Magnetic resonance imaging scan of the upper abdomen also revealed a $9 \times 7.5 \times 7 \mathrm{~cm}$ cortical-parapelvic localized lesion at the lower pole of the left kidney, extending exophytically to the inferior. Given the possibility that the lesion is malignant, nephrectomy was planned. A laparoscopic approach was performed. Histopathological diagnosis was hydatid cyst. Enzyme-linked immunosorbent assay test for hydatid disease was negative. Albendazole $10 \mathrm{mg} / \mathrm{kg}$ twice a day was administered postoperatively for 3 weeks.
\end{abstract}

Keywords: Kidney, cancer, hydatid cyst

\section{INTRODUCTION}

Hydatid cyst disease, also known as echinococcosis, is a parasitic infestation caused by Echinococcus granulosus, a cestode from the Taeniidae family (I). Carnivores, such as wolves, foxes, and especially dogs, are definitive hosts for the parasite, and herbivores, such as sheep, cows, and goats, are intermediate hosts. Humans are incidental hosts. They do not play a role in the transmission cycle and may be infested through contact with a definitive host or oral ingestion of water or vegetables contaminated by the eggs of the parasite. Hydatid disease may affect many parts of the human body. Approximately $40 \%-80 \%$ of patients with primary hydatid disease have single-organ involvement, and it commonly affects the liver (61\%) and lungs (18.7\%) in single-organ involved cases. However, primary kidney hydatid cysts are extremely rare $(2.6 \%)(2)$.

Cysts in the kidney can cause hematuria or flank pain (3). In some patients, as a result of the rupture of the cyst in the collecting system, hydatiduria may occur. The diagnosis is based on imaging and serological tests. In radiological and serological studies, renal hydatid disease cannot be diagnosed preoperatively in l out of 3 patients (4). Here, we present a case of a 45-year-old man with primary renal hydatid disease.

\section{CASE PRESENTATION}

A 45-year-old male patient presented with left flank pain that started a month ago. There was no history of fever or pyuria. His vital signs were normal. Costovertebral angle tenderness was revealed on physical examination. The rest of the systemic examination was unremarkable. He had a history of Behcet's disease, but there was no oral or genital ulcer on admission. Laboratory studies presented normal eosinophil rate (2.7\%), normal renal functions (blood urea I2.7I mg/ $\mathrm{dL}$ and creatinine $0.74 \mathrm{mg} / \mathrm{dl}$ ), and normal liver function tests. There were no pathological findings on urinalysis or urine cytology. Ultrasonography revealed an $8 \times 6.2 \times 6 \mathrm{~cm}$ heterogeneous exophytic trending lesion at the lower pole of the left kidney. The lesion's walls were seen to be calcified in places, and the margin between the kidney and lesion was indistinct. It could not be differentiated by ultrasonography if the lesion is a complicated cyst or a mass. Magnetic resonance imaging (MRI) scan of the upper abdomen also revealed a $9 \times 7.5 \times 7 \mathrm{~cm}$ cortical-parapelvic localized lesion at the lower pole of 
the left kidney, extending exophytically to the inferior (Figure I, 2). There was no significant contrast enhancement on post-contrast study. There was no lymphadenopathy on the para-aortic areas.

Given the possibility that the lesion is malignant, nephrectomy was planned. A laparoscopic approach was performed. Under the left flank position, trocars were placed. After entering the abdominal cavity, the colon was medialized, and the left kidney was dissected from the surrounding tissue. The pedicle was released and clamped using a linear stapler. The kidney was removed through paramedian incision by retrieval pouch.

The specimen measured $13 \times 10.5 \times 9 \mathrm{~cm}$ and weighed $519 \mathrm{~g}$. Adjacent to the upper pole of the kidney, a single, $8 \times 8.5 \times 9 \mathrm{~cm}$ necrotic lesion containing membranes in it was present. Histopathological diagnosis was hydatid cyst. Enzyme-linked immunosorbent assay (ELISA) test for hydatid disease was negative. Albendazole $10 \mathrm{mg} / \mathrm{kg}$ twice a day was administered postoperatively for 3 weeks.

\section{DISCUSSION}

Primary renal hydatid disease is very rare, mostly solitary, and unilateral. The initial phase of primary infection is always asymptomatic. Patients may remain asymptomatic for years (5).

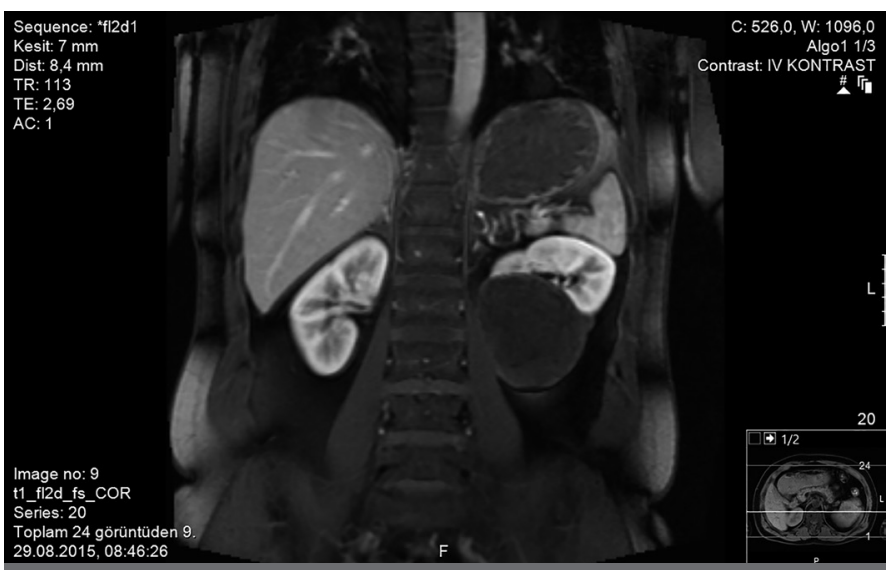

FIGURE I. MRI scan of the upper abdomen also revealed a $9 \times 7.5 \times 7$ $\mathrm{cm}$ cortical-parapelvic localized lesion at the lower pole of the left kidney

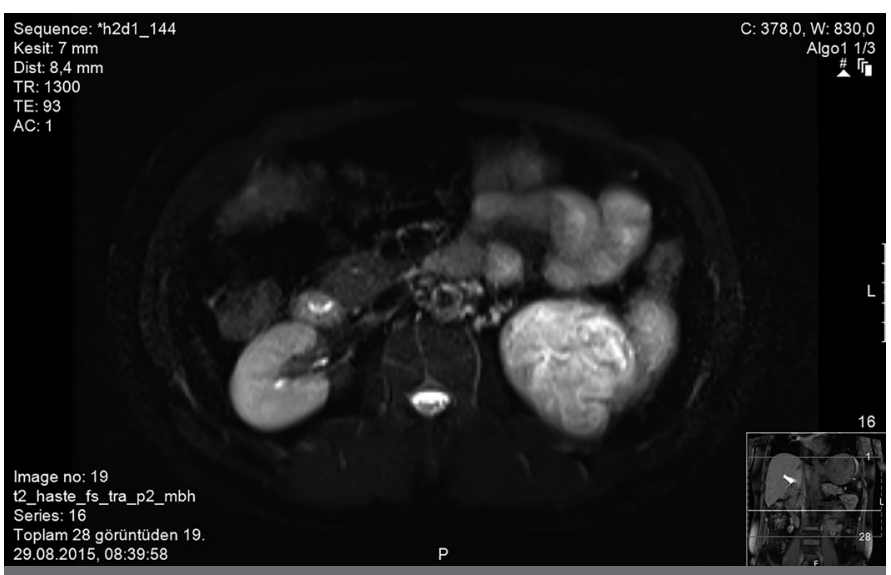

FIGURE 2. MRI scan of the upper abdomen also revealed a $9 \times 7.5 \times 7$ $\mathrm{cm}$ cortical-parapelvic localized lesion at the lower pole of the left kidney
Morbidity mainly depends on different factors, such as dimensions, quantity, and localization of the cyst/cysts. Factors, such as the immune response of the patient and the pressure of the cyst on its surrounding, also affect morbidity. Clinical symptoms, such as flank pain, fever, hematuria, abdominal pain, and weight loss, are non-specific, except gross hydatiduria. Hydatiduria is a pathognomonic sign for the disease and seen in $28 \%-29 \%$ of patients $(6,7)$. It was not detected in our patient.

The diagnosis of hydatid disease is based on the identification of cyst structures by imaging techniques, such as ultrasonography, computed tomography, and magnetic resonance imaging (MRI), and confirmation by immunodiagnostic studies (I). Although its effectiveness depends on the operator, diagnosis is mainly based on ultrasonography due to its advantages, such as cost effectiveness and non-invasiveness. On ultrasonography, renal hydatid cysts are usually detected as a single cystic structure that has a floating membrane and daughter cyst. In our patient's ultrasonography, daughter cyst was not detected, and cyst or mass discrimination of the lesion could not be done. To determine daughter cysts and see the location of the hydatid cyst and its relationship with the surrounding tissue more accurately, computed tomography or MRI can be performed. We performed upper abdominal MRI, and also by MRI, it could not be distinguished if the lesion is a complicated cyst or renal mass.

Serological studies, such as indirect hemagglutination test, ELISA, and indirect fluorescent antibody, are useful in the diagnosis. Fekak et al. (8) demonstrated that serological tests are positive in $55 \%$ of patients. Eosinophilia is reported in $25 \%-50 \%$ of patients (9). Hydatid cysts rarely affect renal function. Our patient's blood creatinine was normal, eosinophilia was not present, and ELISA for hydatid disease was also negative.

Surgical modalities are the main treatment for renal hydatid disease. Surgical procedure should be considered after evaluating the size and localization of the cyst, the relationship with the surrounding tissue, the status of the renal parenchyma, and renal function. Total nephrectomy or kidney-sparing modalities are available techniques, and laparoscopic approach is also an alternative. If preoperative diagnosis is possible, partial nephrectomy can be performed for localized cysts. In our case, owing to the suspicion of renal mass, laparoscopic total nephrectomy was performed.

Primary renal hydatid disease is extremely rare. However, especially in endemic areas, hydatid disease should be taken into consideration for the differential diagnosis of complicated renal cysts. If preoperative diagnosis is possible by imaging and laboratory studies, the preoperative administration of albendazole could be helpful for preventing complications of the probable rupture of the cyst during surgery.

Informed Consent: Written informed consent was obtained from the patient who participated in this study.

Peer-review: Externally peer-reviewed.

Author contributions: Concept - A.C.., H.C.., A.Y., C.T. ; Design - A.C.., A.Y.; Supervision - A.C.., R.A., C.T.; Resource - A.C.., A.Y., H.C.; Materials - A.C. H.C., A.Y., C.T.; Data Collection and/or Processing - A.C., H.C.., A.Y., R.A., C.T.; Analysis and/or Interpretation - A.C.., H.C.., A.Y., C.T.; Literature 
Search - A.Ç., H.Ç., A.Y., C.T.; Writing - A.C.., H.C.., A.Y., R.A., C.T.; Critical Reviews - A.C.., R.A., C.T.

Conflict of Interest: The authors have no conflicts of interest to declare.

Financial Disclosure: The authors declared that this study has received no financial support.

\section{REFERENCES}

I. Eckert J, Deplazes P. Biological, epidemiological, and clinical aspects of echinococcosis, a zoonosis of increasing concern. Clin Microbiol Rev 2004; 17: 107-35. [CrossRef]

2. Demirci E, Altun E, Çalık M, Durur Subașı I, Șipal S, Gündoğdu ÖB. Hydatid Cyst Cases with Different Localization: Region of Erzurum. Turkiye Parazitol Derg 2015; 39: 103-7. [CrossRef]

3. Göğüș C, Safak M, Baltaci S, Türkölmez K. Isolated renal hydatidosis: experience with 20 cases. J Urol 2003; 169: 186. [CrossRef]
4. Gögüs O, Bedük Y, Topukçu Z. Renal hydatid disease. J Urol 1991; 68: 466-9. [CrossRef]

5. Pawlowski, ZS, Eckert J, Vuitton DA, Ammann RW, Kern P, Craig $P S$, at al. Echinococcosis in humans: clinical aspects, diagnosis and treatment. 200I. p. 20-66. In Eckert J, Gemmell MA, Meslin FX, Pawlowski ZS (ed.). WHO/OIE manual on echinococcosis in humans and animals: a public health problem of global concern. World Organisation for Animal Health, Paris, France.

6. Horchani A, Nouira Y, Kbaier I, Attyaoui F, Zribi AS. Hydatid cyst of the kidney. A report of 147 controlled cases. Eur Urol 2000; 38: 46I-7. [CrossRef]

7. Benchekroun A, Lachkar A, Soumana A, Faik M, Marzouk M, Farih $\mathrm{MH}$, at al. Hydatid cyst of the kidney. Report of 45 cases. Ann Urol (Paris) 1999; 33: 19-24.

8. Fekak H, Bennani S, Rabii R, Mezzour MH, Debbaqh A, Joual A, et al. Hydatic kidney cyst: 90 case reports. Ann Urol 2003; 37: 85-9. [CrossRef]

9. Afsar H, Yagci F, Aybasti N, Meto S. Hydatid disease of the kidney. Br J Urol 1994; 73: 17-22. [CrossRef] 